Barbastella 7 (1)

Open Access

ISSN: 1576-9720 SECEMU

www.secemu.org

\title{
Could overheating turn bat boxes into death traps?
}

\author{
Carles Flaquer ${ }^{1}$, Xavier Puig $^{2}$, Adrià López-Baucells ${ }^{1}$, Ignasi Torre ${ }^{1}$, Lídia Freixas ${ }^{1}$, \\ Maria Mas ${ }^{1}$, XaVier Porres $^{3}$, Antoni ArriZabalaga ${ }^{1}$
}

\author{
${ }^{1}$ Granollers Museum of Natural Sciences, Av. Francesc Macià 51, \\ Granollers 08490. Catalonia. \\ ${ }^{2}$ Galanthus Association, Carretera de Juià 46, 17460 Celrà. Catalonia. \\ ${ }^{3}$ Parc Natural del Delta de l'Ebre, Departament de Medi Ambient i Habitatge, \\ Generalitat de Catalunya, Av. Catalunya 64, 43580 Deltebre. Catalonia.
}

Corresponding author e-mail: cflaquer@ajuntament.granollers.cat

DOI: http://dx.doi.org/10.14709/BarbJ.7.1.2014.08

Spanish title: El calentamiento excesivo puede convertir las cajas-refugio en trampas letales?

\begin{abstract}
The placing of bat boxes has become a very popular method of monitoring bats and also an educational tool used by conservation groups and government departments alike to explain the value of bats to human societies. As a result, thousands of bat boxes have been sold or made by bat enthusiasts throughout Europe in past decades. However, very few papers have ever analyzed the importance of temperatures inside bat boxes in light of the expected effects of climate change. This paper is a first attempt to explore the possible effects of extreme heat on bats roosting in boxes.
\end{abstract}

Based on our experience in monitoring bat boxes since 1999, our research team decided to place 10 data loggers in new bat boxes randomly distributed amongst our established box stations to monitor the maximum recorded temperatures in boxes. We established that there was a risk of overheating when temperatures rose above $40^{\circ} \mathrm{C}$. Throughout the whole summer we recorded box temperatures every hour (17,560 readings). Overheating episodes occurred in six of ten boxes and in $2 \%$ of all samples (429 hours). Furthermore, in July 2013 we observed an overheating event in situ when 22 bats fell from a bat box while they were trying to emerge in the evening. Most European bat boxes models are small, have no ventilation and are usually located in places that are exposed to the sun for several hours a day. However, it has been assumed that bats avoid overheating in bat boxes by roost-switching. Nevertheless, in July 2013 we observed bats suffering from overheating in a wetlands where there were many alternative roosting sites (trees and other boxes).

In the Mediterranean area, average summer temperatures are rising annually and we believe it is important to alert bat conservationists to the possibility of overheating events in bat boxes. This preliminary study has indicated that very high temperatures can be reached inside boxes and it is not clear to what extent bats will be able to adapt to these events. Future research should address this issue in the coming years.

Keywords: bats, boxes, monitoring, roosts, overheating, climate change, Pipistrellus pygmaeus, Mediterranean, Europe. 


\section{STATE OF THE ART}

Bat boxes are a popular management tools that can mitigate the loss of roost sites. They are an effective way of increasing roost availability and represent an especially interesting occasion for studying bat distribution and ecology (Racey and Kunz 1998). Bat boxes may play an important role during key phases of bat life cycles and provide a good alternative to natural or artificial roost sites for maternity colonies excluded from buildings (Lourenco and Palmeirim 2004; Flaquer, Torre et al. 2006)

Over the last decade, bat boxes have also been used as an awareness-raising tool by conservationists and thousands have been sold by specialized companies or freely distributed by NGOs and governments. As a result of these educational and/or conservation strategies, many bat boxes have been distributed in the Mediterranean region (Agnelli, Maltagliati et al. 2011). In Europe, bat boxes are mainly small and have few or no compartments (p. ex. Bat Conservation Trust or Schwegler bat box models). In order to improve breeding conditions for maternity colonies, bat boxes need to be placed on southern or eastern exposures (Kerth, Weissmann et al. 2001; Flaquer, Torre et al. 2006; Baranauskas 2013) to increase the sun radiation incidence, whereas western exposures can reach overheating during the mid-day hours in hottest climates (Brittingham and Williams 2000; Flaquer, Torre et al. 2007). Furthermore, some authors suggested using dark-coloured boxes (painted in black) to increase heat absorption (Lourenco and Palmeirim 2004). The correct assessment of both materials and exposures used for bat boxes are also considered to be key factors by according to Bat International Criteria for successful Bat Houses. Differnt colours are recommended regarding climate areas to achive favoralble conditions for maternity colonies in summer, between 27 and $38^{\circ} \mathrm{C}$ internal bat box, (www.batcon.org/pdfs/bathouses/bathousecriteria.pdf). Bats' juvenile growth is dependent on roost temperature during

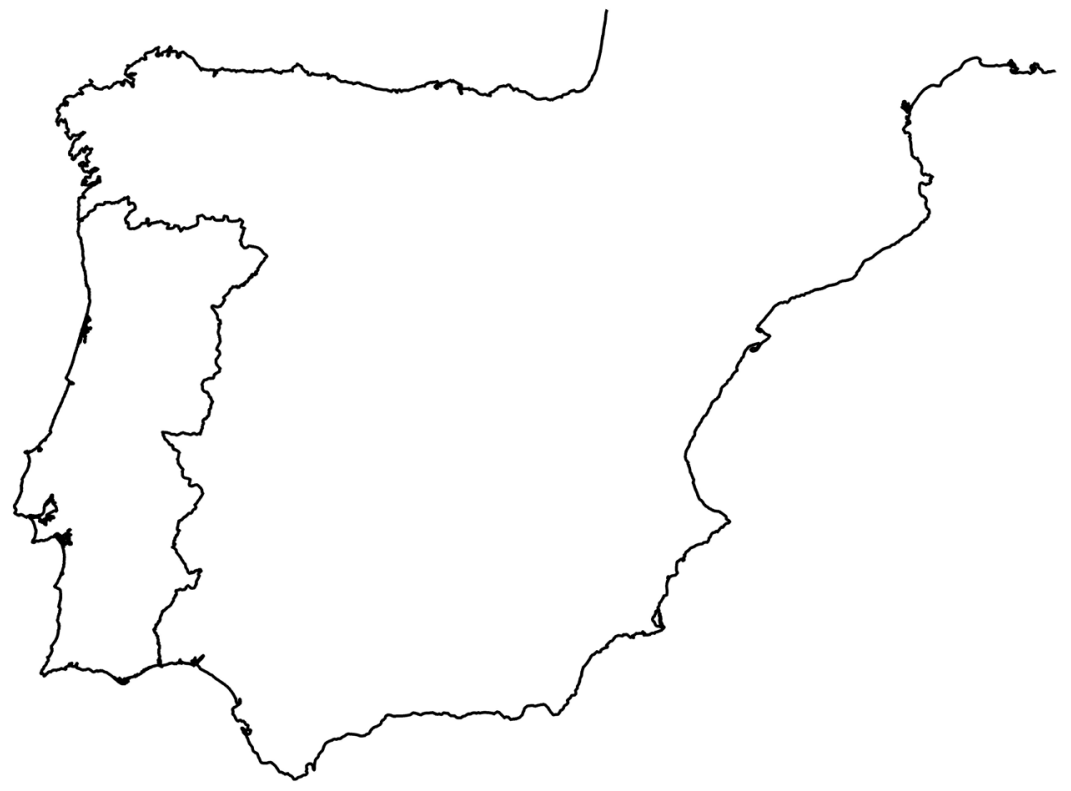

Fig. 1 - Distribution of bat boxes with data loggers in Catalonia in summer 2013. 
both gestation and lactation periods however, few papers to date have ever analyzed how temperatures in bat boxes influence bat breeding strategies (Lourenço and Palmeirim 2004; Bartonicka and Rehak 2007). Those studies that have been conducted consider around $40^{\circ} \mathrm{C}$ to be the maximum temperature tolerated by bats in bat boxes and suggest that bats will switch their roost sites when temperatures are too high (Feyerabend and Simon 2000; Bartonicka and Rehak 2007).

In line with these ideas, in Australia overheating (extreme events over $43^{\circ} \mathrm{C}$ ) have been found to be the cause of the decimation of flying-fox populations, the most affected individuals being basically lactating females and young bats (Welbergen, Klose et al. 2008). Temperature extremes are inherent expressions of climate change due to their direct link with the increased heat content of the atmosphere (IPCC 2007)

The effect of extreme heat events on microchiroptera in temperate zones is still unknown and their capacity as bioindicators still needs to be properly studied (Flaquer and Puig-Montserrat 2012). During the past two years some exceptional events have alerted us to possible overheating die-offs in the soprano pipistrelle bat Pipistrellus pygmaeus (Leach 1825) breeding in bat boxes. This paper discusses this important subject that could become problematic due to the current trend for rising temperatures.

\section{Collecting evidence}

\section{Field observation}

Our research team has been surveying bat boxes in Catalonia in both natural areas and urban environments since 1999. The climate throughout the region is Mediterranean (mean annual temperatures of ca. $16^{\circ} \mathrm{C}$; average precipitation of 500-700 mm/year). During the 10 years of this monitoring program, we have observed on occasions that some bat breeding colonies remain outside bat boxes and that some individuals sweat considerably; however, we neither found nor expected any mortality to be linked to this behaviour. No specific effort has ever been carried out to evaluate the effect of high temperatures on bats in artificial roost sites (either on a daily or annual basis).

In summer 2008 almost the whole of a breeding colony of Pipistrellus pygmaeus (42 individuals) were found dead inside bat boxes located in a wetland without any obvious explanation. In the same location but in a different bat box in July 2013 we observed in situ several bats fall out of a bat box while they were trying to emerge. This event happened in the afternoon at 17:00h in a wooden bat box located on a building (UTM: 42.218726, 3.100475), facing west and surrounded by trees (which reduced sun exposure at midday). Of the bats, 22 were collected and sent to a rescue centre where they were rehydrated and released at night (two of them subsequently died).

\section{Small-scale experiment}

In 2013 we decided to place 10 data loggers (iButton DS1922L) inside new small wooden bat boxes $(n=9)$ without compartments $(100 \times 190 \times 200 \mathrm{~mm})$ (Flaquer, Torre et al. 2006) and inside a single Schwegler Bat Box model 1FF. All bat boxes were randomly deployed in eight locations in Catalonia close to bat-box monitoring areas (Fig. 1). Bat boxes were situated from sea level ( 5 m.a.s.l.) to $990 \mathrm{~m}$, and facing to favorable exposures: South, East, and West (Berthinussen, Richardson et al. 2008). Data loggers were programmed to record temperatures hourly every day from July to mid-September 2013, which gave a total of 17,560 temperature readings. Data loggers recorded temperatures on average along 54.1 days \pm 19.9 (SD), ranging between 24 and 77 days.

Temperatures recorded in the Schwegler bat box were compared with the wooden bat box under similar circumstances; in addition, data from two wooden bat boxes - one placed on a pole and the other on a wall - at same site

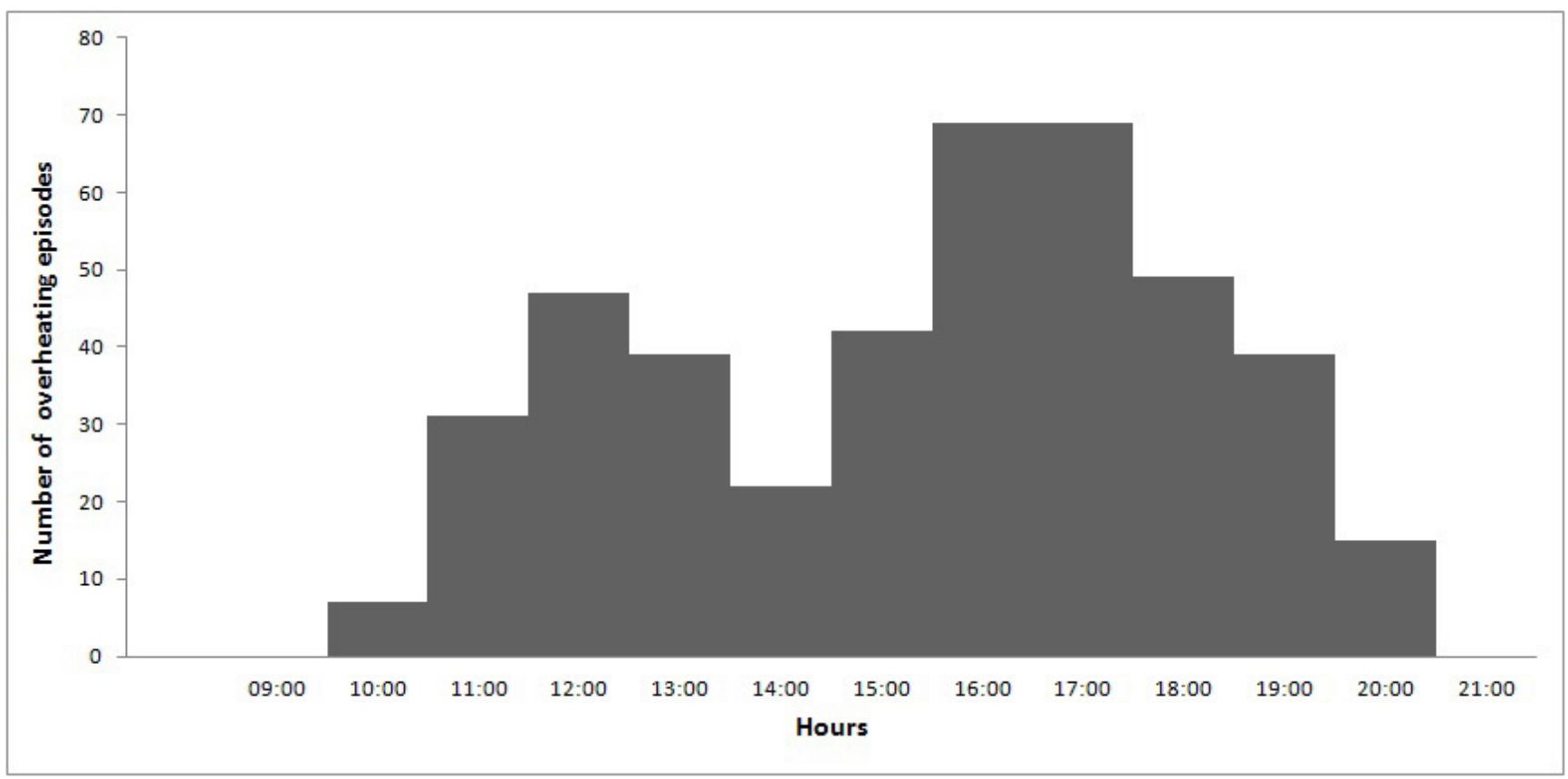

Fig. 2 - Distribution of overheating episodes (sample per hour) recorded at all data loggers $(n=10)$ and the time at which these episodes occurred. 


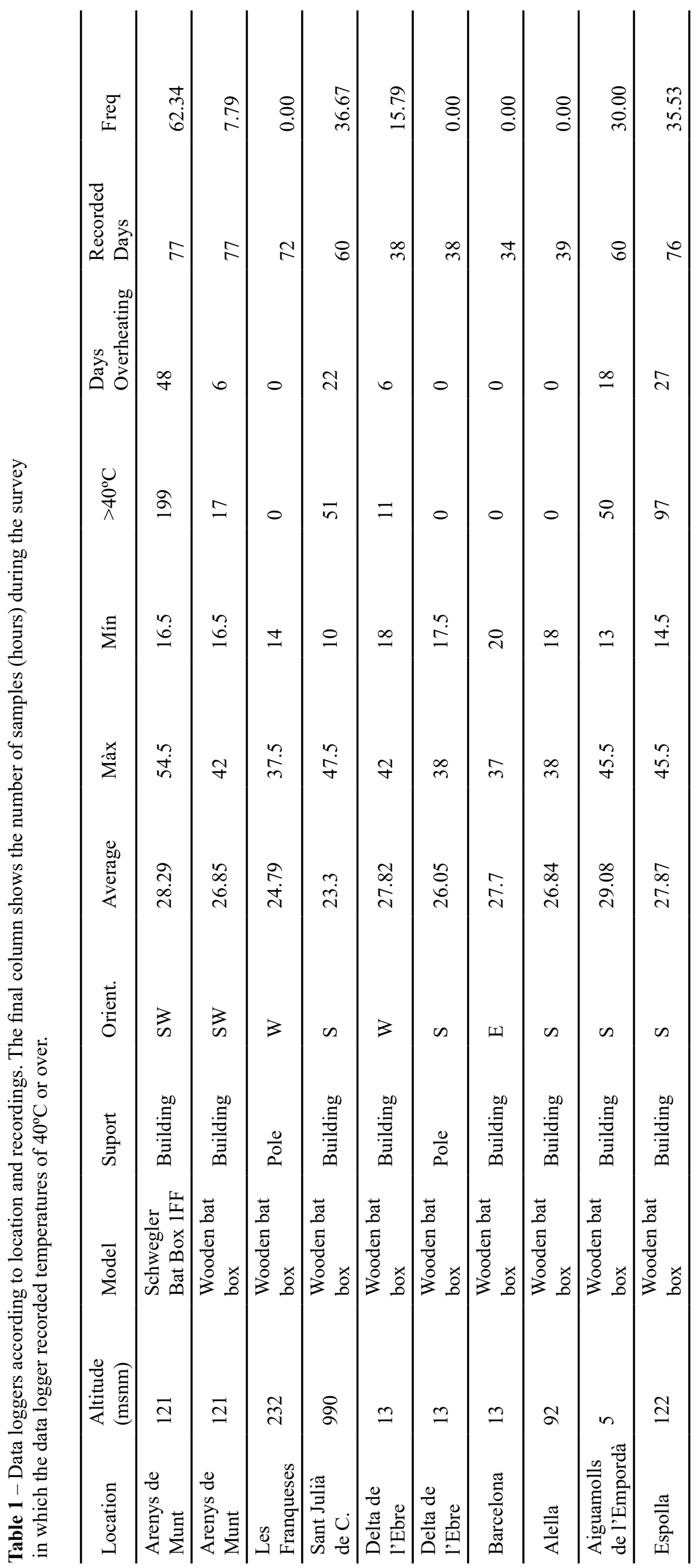

were compared. Since temperature data were non normally distributed, we used the Wilcoxon matched pairs test.

\section{SOME CLUES AND PRELIMINARY RESULTS}

$60 \%$ of all bat boxes recorded temperatures above $40^{\circ} \mathrm{C}$ at least once during the experiment (Table 1). Even at high altitudes (990 $\mathrm{m}$ a.s.1.) temperatures inside bat boxes rose to $47^{\circ} \mathrm{C}$ and overheating episodes occurred from 10.00 to $20.00 \mathrm{~h}$ (Fig. 2). Overheating episodes were only observed in bat boxes placed on walls, whereas none of the two bat boxes placed on poles experienced overheating. When the box was placed on a wall, maximum temperatures were $4^{\circ} \mathrm{C}$ higher than on a pole (Fig. 3). The Wilcoxon matched pairs test confirmed that Schwegler bat box recorded higher temperatures than Wooden bat box under the same sun exposure situation $(\mathrm{Z}=17.27, \mathrm{p}<0.0001, \mathrm{n}$ $=1728)$. Mean temperatures were $1.5^{\circ} \mathrm{C}$ higher in the former box $(\mathrm{X}=$ $28.25^{\circ} \mathrm{C} \pm 7.73$, range $16.5-54.5^{\circ} \mathrm{C}$, Coefficient of variation $\mathrm{CV}=27.3 \%$, and $\mathrm{X}=26.83^{\circ} \mathrm{C} \pm 5.05$, range 16.5 $42.0^{\circ} \mathrm{C}, \mathrm{CV}=18.8 \%$, respectively). In the Schwegler Bat Box maximum temperatures were $12^{\circ} \mathrm{C}$ higher than the wooden boxes under similar situation. Schwegler bat box recorded overheating episodes during 48 days (199 temperature records), representing the $62.3 \%$ of the study period, but the wooden bat box only recorded overheating episodes on six days $(7.6 \%$ of the study period). Air temperature recorded was similar for both bat boxes between 0:00 and 14:00 hours, and differed between 16:00-22:00 hours in the hottest summer months (July and August, Fig. 4). During the first two weeks of September, no significant temperature differences were recorded between both bat boxes. 


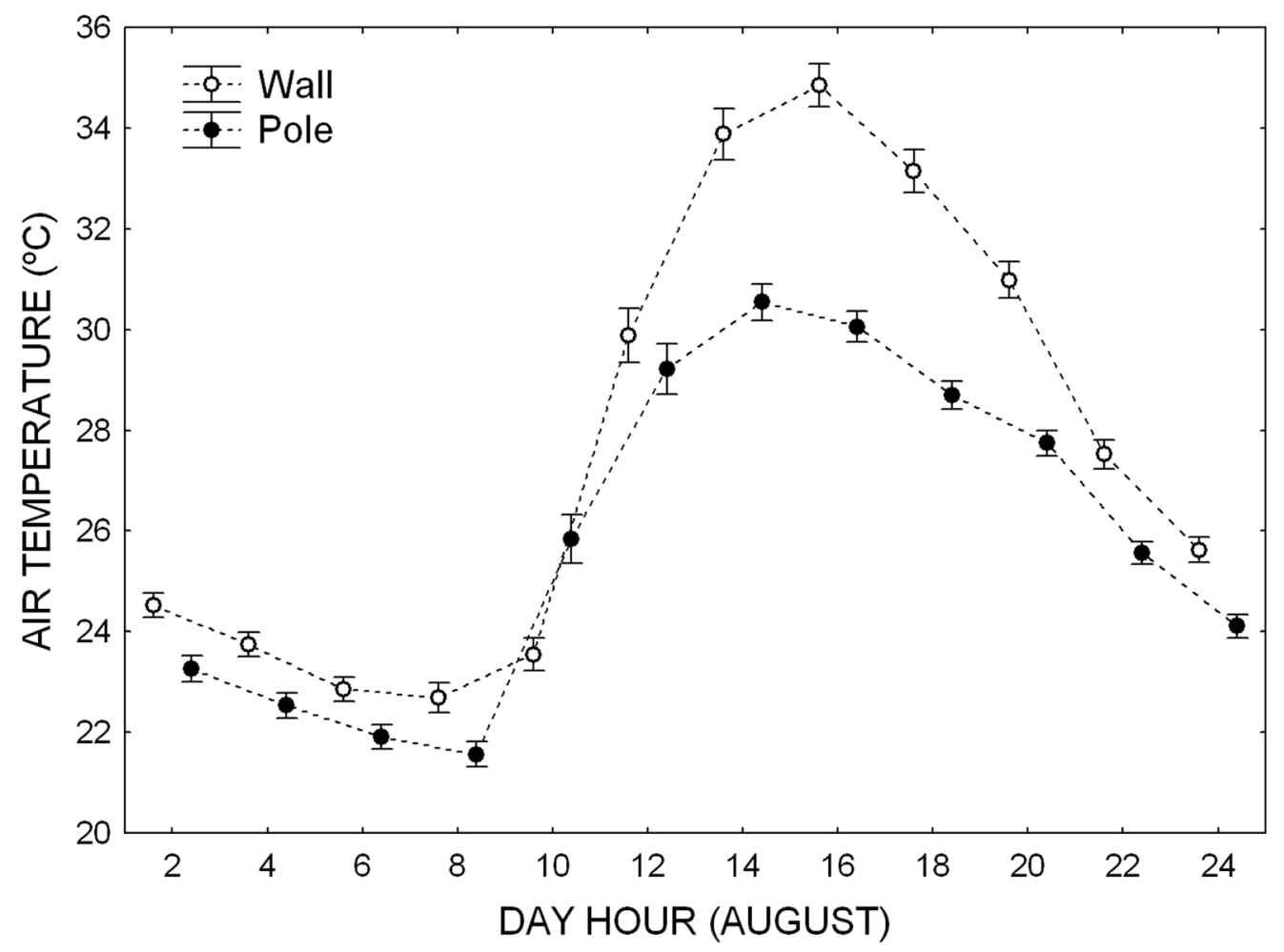

Fig. 3 - Comparison between temperatures recorded in a bat box located on a wall and one hung on a pole at the same location with similar orientation (SW/S).
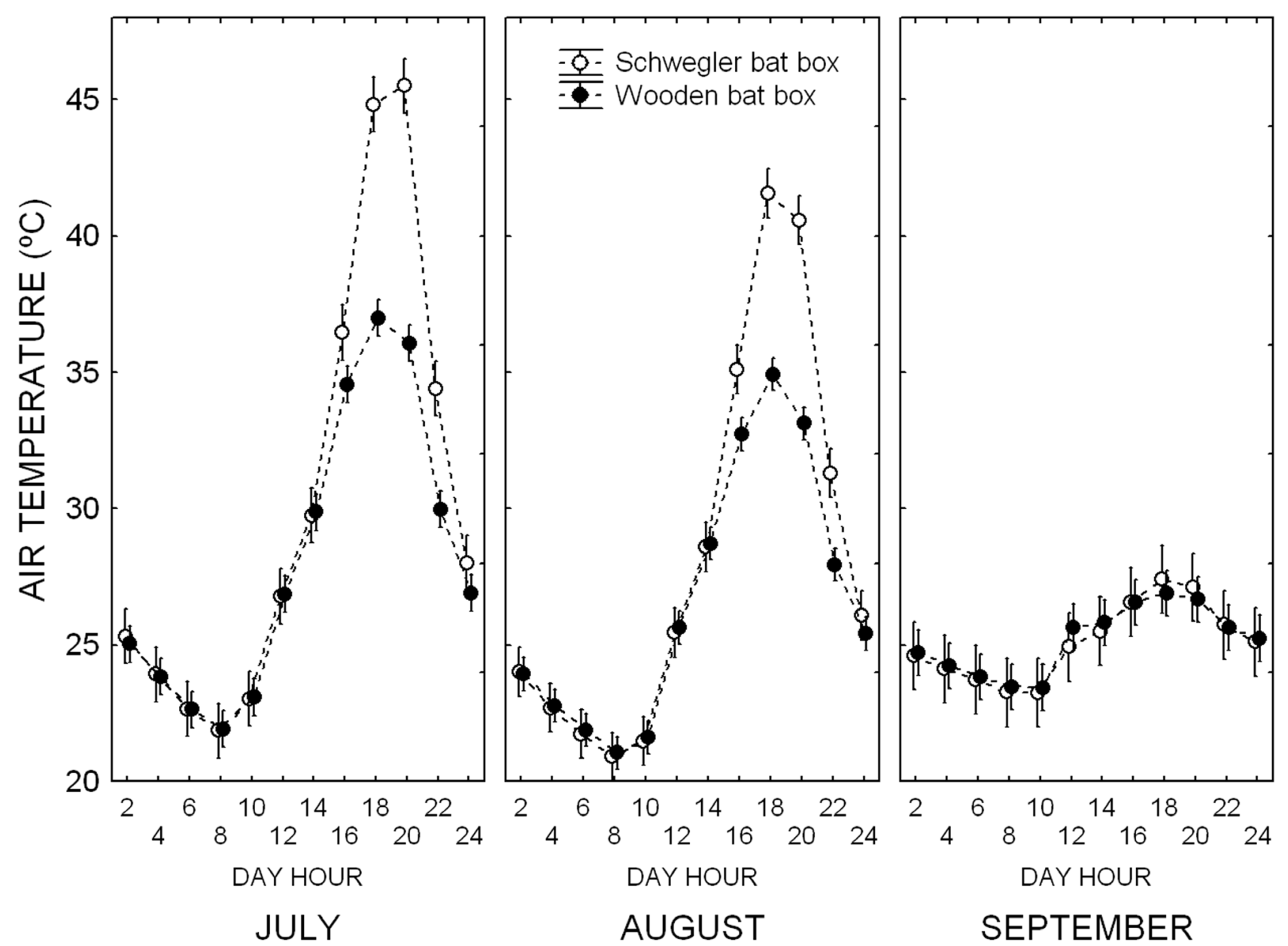

Fig. 4 - Comparison between temperatures recorded in a Schwegler Bat Box model 1FF and a wooden bat box at the same location and on the same support (wall). 


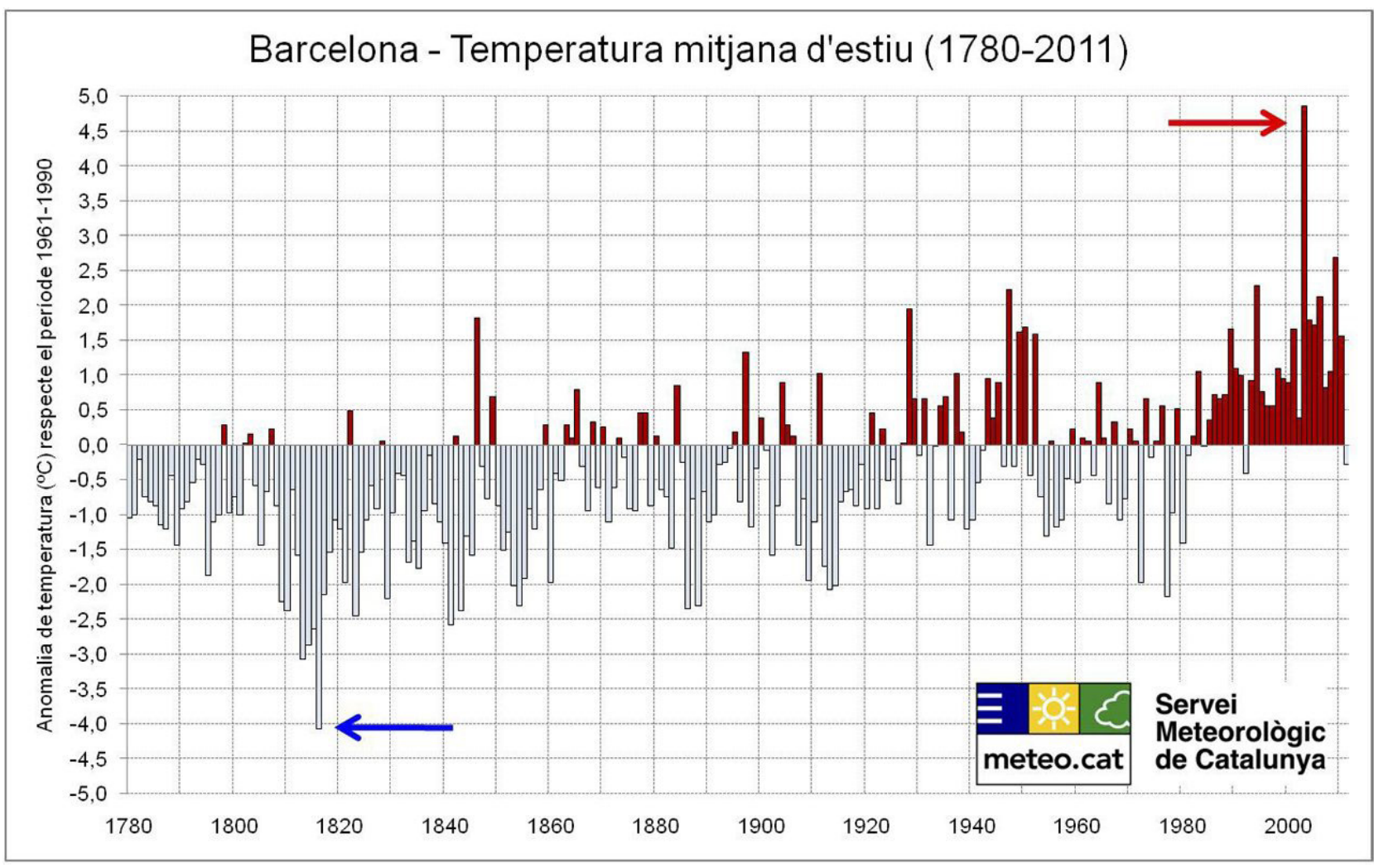

Fig. 5 - Anomaly temperatures $\left({ }^{\circ} \mathrm{C}\right)$ recorded in Barcelona from 1780 to 2011 compared with average temperatures. Over the last 30 years almost all these anomalies correspond to hotter events.

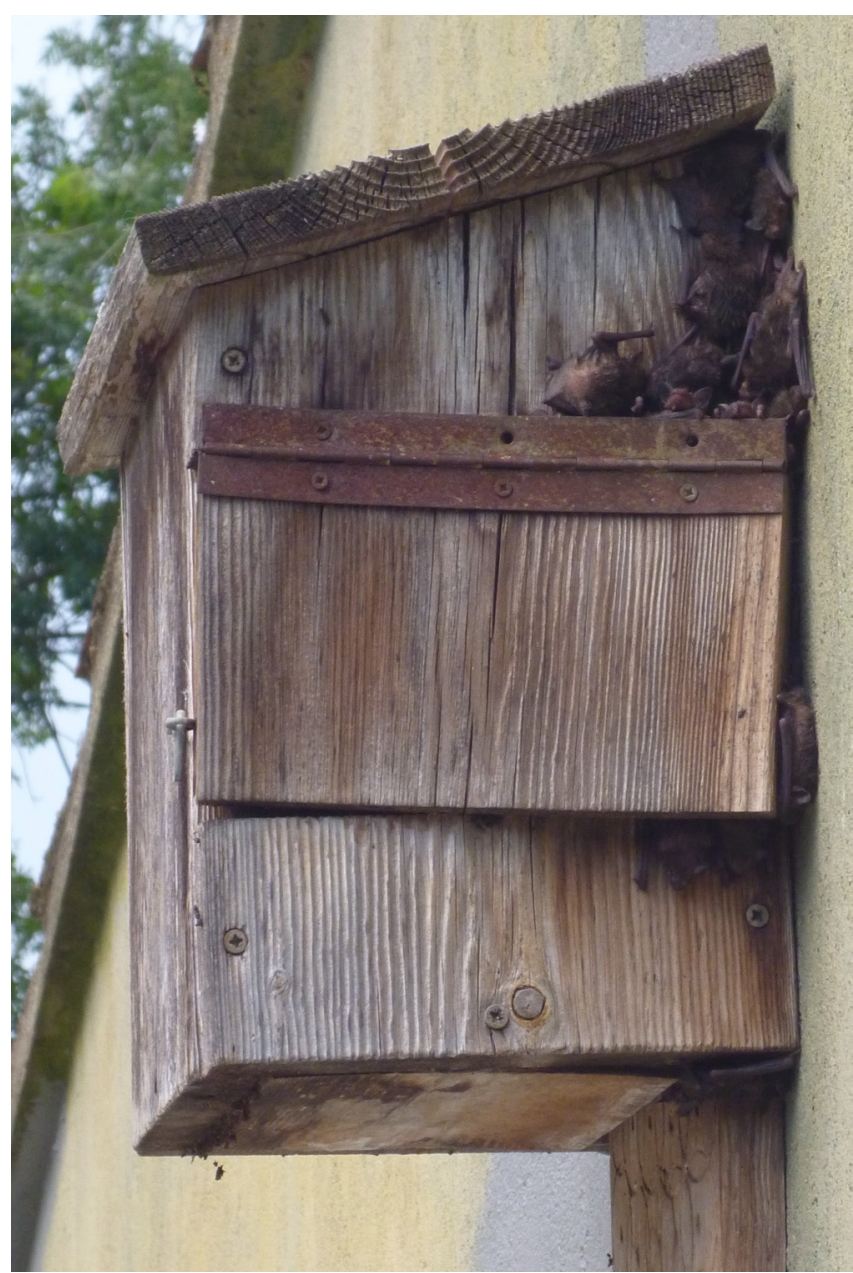

Fig. 6 - Bat-box overheating event witnessed in the Aiguamolls de l'Empordà Natural Park in July 2013. All the bats where collected from the ground and then rehydrated..

\section{DiscUSSION AND AWARENESS}

As bat conservationists and researchers we have always considered bat boxes to be an excellent tool for both management and education. According to the bibliography, boxes should be placed from south-east to south-west situations that are well exposed to the sun (http://www.bats. org.uk/pages/bat boxes.html; (Berthinussen, Richardson et al. 2008), and some authors encourage using dark colours to increase heat absortion (Lourenco and Palmeirim 2004). The models we have been using are inspired and personally designed according to the available information from Europe, and are mostly small and without ventilation. The bat boxes on sale in the Mediterranean are likewise essentially small without any ventilation and, in some cases, are painted black, like the Schwegler bat box.

In the Mediterranean area, average summer temperatures are rising year by year (Fig. 5) and, although there is no doubt that extreme heat events have increased in frequency in the past decade, their potential negative consequences are still unknown. (Welbergen, Klose et al. 2008).

According to (Bartonicka and Rehak 2007), "we cannot assume that box overheating is a possible risk. Box overheating may not be so dangerous if sufficient supplies of alternative roosts, mainly tree cavities, are available in the vicinity". Yet, we have directly observed an overheating event in a bat box that caused fatalites. It should be taken into account that this episode occurred in a wetland (guaranteed high humidity) and that there were several other bat boxes in the area, as well as trees and buildings. In other Mediterranean wetland (Ebro delta), P.pygmaeus mainly selected bat boxes exposed to the East than to the West (Flaquer et al. 2006). 
Some preliminary records with data loggers in this area showed that bat boxes exposed to the west recorded higher temperatures during mid-day hours, with several episodes of overheating (Flaquer, Torre et al. 2007).

Furthermore, the use of different materials to build up the bat boxes need to be properly examined. Our results point out that bat boxes painted on dark colours and made of woodcrete are extremely hot and the range of temperatures recorded are more variable than those recorded in bat boxes made on wood. The value of the former bat boxes in the conservation of bat populations in Mediterranean habitats can be questioned, despite these are amongst the most selled models in Catalonia.

There are thus a number of unanswered questions that must be addressed and properly studied:

1. How dangerous might box overheating be in light of the trend towards increased temperatures occurring as a result of climate change?

2. Can we be sure that bats use the strategy of roostswitching when temperatures are rising rapidly?

3. Can the models of bat boxes available in Europe properly thermoregulate and so avoid overheating episodes above $40^{\circ} \mathrm{C}$ ?

4. Should we change recommendations like "... exposed to sunlight for as much of the day as possible to increase bat box internal temperature" (Bat Conservation Trust recommendation to the best place to position the box to general public)?

For the time being not enough data are available to provide answers to these questions, although, when we observed bats falling out of a bat box due to overheating, we realized that our suspicions were well founded (Fig. 6). The results of our tests with data loggers are even more worrying as they show that bat boxes located in Mediterranean mountain areas can reach high temperatures if they are located on south-facing buildings (Table. 1).

We hope that this paper will encourage bat workers and researchers to collect as much information on the subject as possible over the coming years. If necessary, changes in batbox management protocols may have to be implemented.

\section{ACKNOWLEDGements}

This Project received financial support from the Catalan Office for Climate Change, Diputació de Barcelona, Diputació de Girona, Generalitat de Catalunya and the Granollers Natural History Museum. We are especially grateful to the Ebro Delta and Aiguamolls de l'Empordà natural parks, to l'Albera Natural Area of National Interest, and to the Collserola, Serralada de Marina and Serralada Litoral parks. We are particularly indebted to the support provided by B. Borràs, G. Borràs, L. Cabañeros, T. Curcó, J. Justafré, R. Loire, F. Llimona, B. Minobis, I. Pac, S. Romero, S. Samitier and F. Vidal.
Finally, we would like to make special mention of Dr. Danilo Russo, who has been acting as our mentor during this ongoing, formative period of research.

\section{REFERENCES}

Agnelli, P., Maltagliati, G., Ducci, L., Cannicci, S. 2011. Artificial roosts for Bats: Education and Research. The "Be a bat's friend. Project of the Natural History Museum of the University of Florence. HystrixItalian Journal of Mammalogy 22(1): 215-223. DOI: https://dx.doi.org/10.4404/hystrix-22.1-4540

Baranauskas, K. 2013. Diversity and Abundance of Bats (Chiroptera) found in Bat Boxes in East Lithuania. Acta Zoologica Lituanica 20(1): 39-44. DOI: https://dx.doi,org/10.2478/v10043-010-0005-8

BARTONICKA,T., REHAK,Z.2007. Influence of themicroclimate of bat boxes on their occupation by the soprano pipistrelle Pipistrellus pygmaeus: possible cause of roost switching." Acta Chiropterologica 9(2): 517-526. DOI: http://dx.doi.org/10.3161/17335329(2007)9[517:IOTMOB]2.0.CO;2

Berthinussen, A., Richardson, O. C., Altringham, J. D. 2008. Bat Conservation. Global evidence for the effects of interventions. Synopses of Conservation Evidence. London, Pelagic Publishing. Volume 5.

Brittingham, M. C., Williams, L. M. 2000. Bat boxes as alternative roosts for displaced bat maternity colonies. Wildlife Society Bulletin 28(1): 197-207.

Feyerabend, F., Simonm, M. 2000. Use of roostsand roost switching in a summer colony of $45 \mathrm{kHz}$ phonic type pipistrelle bats (Pipistrellus pipistrellus Schreber,1774). Myotis 38: 51-59.

Flaquer, C., Puig-Montserrat, X. 2012. Proceedings of the International Symposium on the Importance of Bats as Bioindicators. Granollers, Granollers Museum of Natural Sciences Edicions.

Flaquer, C., I. Torre, Arrizabalaga, A. 2007. Selección de refugios, gestión forestal y conservación de los quirópteros forestales. In: Conservación de la biodiversidad, fauna vertebrada y gestión forestal. J. Camprodon and E. Plana Eds. Barcelona, Universitat de Barcelona: 469-488.

Flaquer, C., Torre, I., Ruiz-Jarillo, R. 2006. The value of bat-boxes in the conservation of Pipistrellus pygmaeus in wetland rice paddies. Biological Conservation 128(2): 223-230. DOI: https://dx.doi. org/10.1016/j.biocon.2005.09.030

IPCC (2007). Climate Change 2007: The hisical science basis. Contribution of Working group I to the Fourth Assessment Report of the Intergovernmental Panel on Climate Change. Cambridge Cambridge University Press. 
Kerth,G.,Weissmann,K.,Konig,B.2001.Dayroostselection in female Bechstein's bats (Myotis bechsteinii): a field experiment to determine the influence of roost temperature. Oecologia 126(1): 1-9. DOI: https:// dx.doi.org/10.1007/s004420000489

Lourenço, S. I., Palmeirim, J. M. 2004. Influence of temperature in roost selection by Pipistrellus pygmaeus (Chiroptera): relevance for the design of bat boxes. Biological Conservation 119(2): 237-243. DOI: https://dx.doi.org/10.1016/j. biocon.2003.11.006
Racey, P., Kunz, T. H. 1998. Bat biology and conservation. Washington, Smithsonian Institution Press.

Welbergen, J., Klose, S., Markus, N., Eby, P. 2008. Climate change and the effects of temperature extremes on Australian flying-foxes. Proceedings of the Royal Society of Biological Sciences 275: 419-425. DOI: https://dx.doi.org/10.1098/rspb.2007.1385 